\title{
Особенности моделирования интегрально-оптических элементов для радиофотоники
}

\author{
А.В. Царев ${ }^{1,2}$, Р.М. Тазиев ${ }^{1}$ \\ ${ }^{1}$ Институт физики полупроводников им. А. В. Ржанова СО РАН, г. Новосибирск, \\ 630090, пр. Академика Лаврентьева, 13 \\ ${ }^{2}$ Новосибирский государственный университет, г. Новосибирск, \\ 630090, ул. Пирогова, 2 \\ тел:+7 9134810 578, факс:+7 (383) 333-2771, эл. почта: tsarev@isp.nsc.ru
}

DOI 10.34077/RCSP2021-86

B работе обсуждаются результаты численного моделирования волноводных электрооптических модуляторов, использующих различные физические эффекты. Это модуляторы на электрооптических полимерах с возможностью снижения до 2.5 раз управляющего напряжения за счет применения замедляющих диэлектрических полосок [1], кремниевых модуляторов с вертикальным p-n переходом с низким управляющим напряжением [2], модуляторов на основе квантово-размерного эффекта Штарка в свехрешетках на основе двухслойных волноводов на основе фосфида индия с возможностью эффективного согласования излучения с оптическим волокном [3]. Основные выводы проиллюстрированы методами численного моделирования с использование оптического пакета от Rsoft [4].

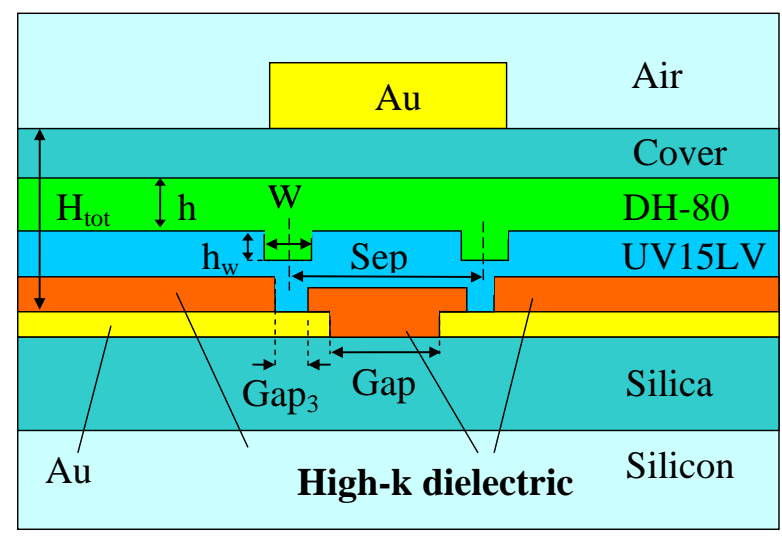

a)

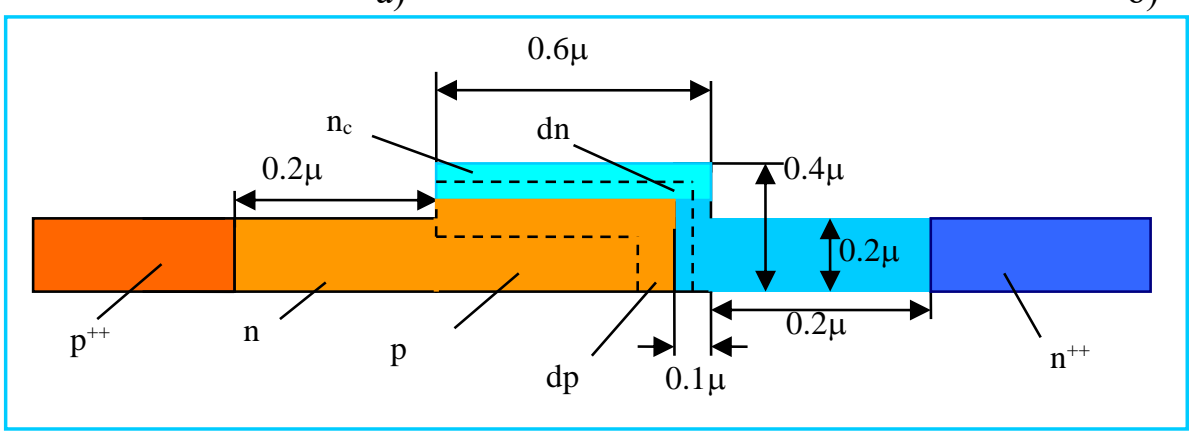

B)

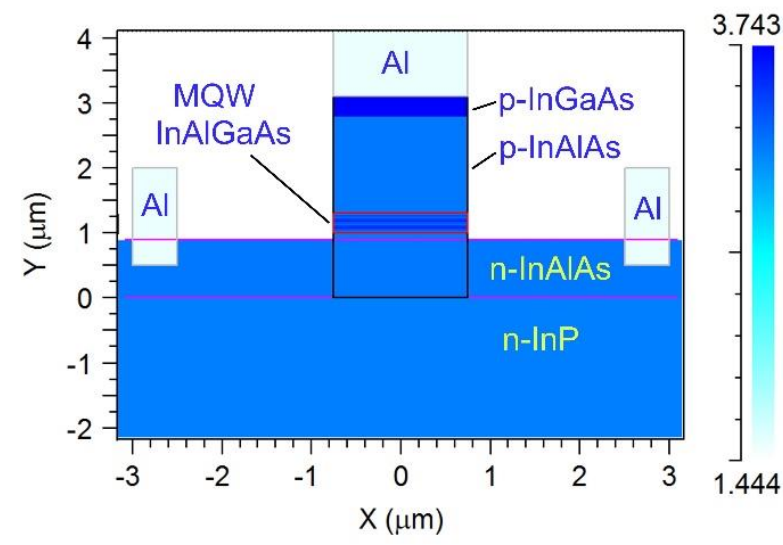

б)

Рис. 1. Примеры электрооптических модуляторов, которые моделируются с использованием оптического пакета от Rsoft [4]. a) Электрооптический модулятор с полосками из изолирующего материала с высокой диэлектрической проницаемостью; б) Электрооптический модулятор с квантовыми ямами на сверхрешетке $\mathrm{In}_{0.52} \mathrm{Al}_{0.09} \mathrm{Ga}_{0.38} \mathrm{As} / \mathrm{In}_{0.53} \mathrm{Al}_{0.3} \mathrm{Ga}_{0.17} \mathrm{As}$ на подложке фосфида индия; в) электрооптический модулятор в структуре кремний на изоляторе с обратными p-n переходом.

\section{Лumepamypa}

[1] A. Tsarev, et al // Photonics and Nanostructures - Fundamentals and Applications. 2017. V. 25, P.31-37.

[2] А.В. Царев, Р.М. Тазиев // Квантовая электроника. 2019, Т. 49, вып.11, С.1036-104.

[3] А.В. Царев, Р.М. Тазиев // Квантовая электроника. 2019, Т. 49, вып.3, С. 266-271.

[4] Rsoft by SYNOPSYS (https://optics.synopsys.com/rsoft/), single license (2020). 